\title{
Helicobacter pylori and radical therapy for peptic ulcer
}

The high prevalence of Helicobacter pylori infection in apparently healthy humans complicates the established definite link with disease in the minority. Disputes over whether the organism is acquired in early years of life (cohort effect) or whether it increases continuously with age should not obscure the fact that recurrent infection is unlikely in adults. ${ }^{1-4}$ An attempt at eradication is, therefore, reasonable when the organism is clinically important for individual patients. The important questions are whom to treat and with what?

\section{Duodenal ulcer}

Duodenal ulcers can be effectively healed by proton-pump inhibitors such as omeprazole or lansoprazole given for four weeks, or histamine $\mathrm{H} 2$ receptor antagonists such as ranitidine or cimetidine for six to eight weeks. Most patients have a relapse of ulceration after initial healing therapy, so that preventive measures are appropriate. Almost all duodenal ulcers are associated with $H$ pylori infection, and it is this combined with gastric acid which causes the ulcer to recur. The rate of relapse can be dramatically cut by clearing $H$ pylori infection and this is now a prime objective in patient management. The US National Institutes of Health recommended in February 1994 that all peptic ulcer patients should be considered for anti- $H$ pylori therapy.

Although clearance of $H$ pylori without formal anti-acid therapy should heal duodenal ulcer permanently, the variable success rates with some of the regimes used suggests that a combined approach is correct. ${ }^{5,6}$ To guarantee almost complete healing and at least $90 \%$ long-term cure rate, a convenient regime is to use a full course of proton-pump inhibitor with two antibiotics for a week. One way of doing this is to give a one-month course of lansoprazole $30 \mathrm{mg}$ daily and simultaneously in the first week amoxycillin $500 \mathrm{mg}$ tid plus metronidazole $400 \mathrm{mg}$ tid OR clarithromycin $250 \mathrm{mg}$ bid plus tinidazole $500 \mathrm{mg}$ bid. ${ }^{7}$ At the time of writing the cost is $£ 36$ or $£ 56$, respectively, and the side-effect rate is low, although diarrhoea may occur.

Alternatively, omeprazole can be given in a dose of $40 \mathrm{mg}$ daily for a week with two antibiotics. ${ }^{8}$ The course could be completed with a further three weeks of omeprazole $20 \mathrm{mg}$ daily, but this is both more complex and more expensive.

Another option which might be used in refractory or recurrent ulcers and continuing $H$ pylori infection is quadruple therapy. ${ }^{9,10}$ This involves using omeprazole for a month and giving bismuth, tetracycline and metronidazole for the first week. This has yielded $95-98 \% H$ pylori eradication rates and appears to avoid the toxicity associated with the use of bismuth, tetracycline and metronidazole alone as triple therapy for two weeks as previously recommended.

To ensure that therapy has succeeded, it is necessary to check at least one month after it has all been completed. Carbon-13 or carbon-14 urea breath tests are a convenient non-invasive way of achieving this. If patients attend for review endoscopy then biopsies taken for direct urease tests are an alternative, but do need to be taken from the fundus or body as well as from the antrum of the stomach as differential clearing may occur. Serology using IgG
ELISA is not very useful as it requires a sample before therapy and then 6 to 12 months later, which introduces impractical complications.

Where treatment does not produce negative $H$ pylori tests further antibiotic therapy may need to be considered. It is best to use different drugs to avoid the problem of induced resistance to clarithromycin and nitroimidazoles as far as possible, but the best results have been achieved with regimes which include at least one of these agents. The notional problem of primary or secondary resistance to metronidazole or tinidazole may have been overstated for technical reasons. Optimal culture conditions for $H$ pylori are not necessarily those required to demonstrate antibacterial sensitivity. ${ }^{11,12}$

Modern regimes should consistently achieve $90 \%+$ eradication rates, and it is unsatisfactory to use treatment with lesser success. This means that dual therapy with omeprazole and amoxycillin or clarithromycin cannot really be recommended now. ${ }^{3}$ Average success rates using one antibiotic plus a proton-pump inhibitor have been only about $60-80 \%$ unless very large doses of omeprazole are used. Similarly, disappointingly low success rates have been achieved overall using triple therapy with bismuth, tetracycline and metronidazole. ${ }^{1,5}$ Some regimes which have been effectively used to eradicate $H$ pylori include one-week treatments with omeprazole, amoxycillin and metronidazole; omeprazole, amoxycillin and clarithromycin; omeprazole, clarithromycin and metronidazole; and omeprazole, clarithromycin and tinidazole..$^{5,13}$

\section{Gastric ulcer}

Proton-pump inhibitor therapy for eight weeks is standard therapy, and antibiotic treatment for the first week should be added to this. A convenient regime is to use lansoprazole $30 \mathrm{mg}$ for two months and amoxycillin $500 \mathrm{mg}$ tid plus metronidazole $400 \mathrm{mg}$ tid or clarithromycin $250 \mathrm{mg}$ bid plus tinidazole $500 \mathrm{mg}$ bid for the first week. It is very important to prove healing endoscopically and if this is done a month after all therapy is completed it is convenient to test $H$ pylori eradication by biopsy and direct urease testing.

It is uncertain whether it is necessary to obtain proof of $H$ pylor $i$ infection before therapy and analysis of any tests may be misleading for various technical and clinical reasons. In gastric ulcers more prolonged anti-acid therapy may be subsequently required and it is crucial to prove complete healing to avoid the risk of missing malignancy.

\section{Lymphoma}

There is no lymphoid tissue in the normal human stomach, and the local mucosa-associated lymphoid tumour (MALToma) is reckoned always to follow $H$ pylor $i$ infection. This is a rare condition and though cure of the infection may lead to tumour regression, the large majority of patients will need surgical resection or perhaps radiotherapy to ensure cure. $^{14}$

\section{Other indications}

$H$ pylori is a normal passenger in many adults. For example over $50 \%$ of adults between the ages of 50 and 70 years are 
carriers in Western society. This means it will be an incidental finding in many patients with dyspepsia. There is no conclusive evidence that antibiotic therapy helps control symptoms. ${ }^{15-17}$ If patients who have antral gastritis, or who have been on prolonged anti-acid therapy, are offered anti-H pylori treatment it must be clearly understood by them and their physicians that this is a calculated experiment.

Although there was initially some doubt as to whether bleeding peptic ulcers could be safely managed with anti- $H$ pylori therapy rather than prolonged anti-acid treatment, it is now known that this is a useful technique. ${ }^{18,19}$

\section{Cases in which treatment should be avoided}

The epidemiological evidence incriminating $H$ pylor $i$ in the causation of gastric adenocarcinoma and ischaemic heart diseases has attracted a lot of attention and is exciting. However, for individual patients with these conditions anti- $H$ pylori treatment will not be of benefit.

1 Veldhuyzen van Zanten SJ, Pollak PT, Best LM, Bezanson GS, Marrie T. Increasing prevalence of Helicobacter pylori infection with age: continous risk of infection in adults rather than cohort effect. $\mathcal{F}$ Infect Dis 1994; 169: 434-7.

2 Blecker U, Lanciers S, Hausier B, Vandenplas Y. The prevalence of Helicobacter pylori positivity in a symptom-free population, aged 1 to 40 years. $f$ Clin Epidemiol 1994; 47: 1095-8.

3 Penston JG. Helicobacter pylori eradication - understandable caution but no excuse for inertia. Aliment Pharmacol Ther 1994; 8: 369-89.

4 Phull PS, Ryder SD, Halliday D, Price AB, Levi AJ, Jacyna MR. The Phull PS, Ryder SD, Halliday D, Price AB, Levi AJ, Jacyna MR. The economic and quality-of-life benefits of Helicobacter pylori eradication in
chronic duodenal disease - a community-based study. Postgrad Med $\mathcal{F} 1995$; 71: 413-8.

5 Marshall BJ. Helicobacter pylori. Am f Gastroenterol 1994; 8: S116-S128. 6 Tytgat GNJ. Treatments that impact favourably upon the eradication of Helicobacter pylori and ulcer recurrence. Aliment Pharmacol Ther 1994; 8: 359-68.

7 Bateson MC, Diffey BL. Radical therapy for duodenal ulcer. Gut 1995; 36: S35.

8 Bell GD, Powell KU, Burridge SM, et al. Rapid eradication of Helicobacter pylori infection. Aliment Pharmacol Ther 1995; 9: 41-6.

9 De Boer W, Driessen W, Jansz A, Tytgat G. Effect of acid suppression on efficacy of treatment for Helicobacter pylori infection. Lancet $1995 ; 345$ 817-20.

10 Hosking SW, Ling TKW, Yung MY, et al. Randomised controlled trial of short-term treatment to eradicate Helicobacter pylori in patients with duodenal ulcer. $B M F$ 1992; 305: 502-4.
It is even more contentious whether $H$ pylori immunisation or antibiotic treatment could be used to reduce the already falling rates of gastric carcinoma and ischaemic heart disease in Western societies. It would be very difficult to prove an effect at all, and even if there were one most of the present generation of doctors would be retired long before it could become apparent.

Since induced resistance will inevitably become a problem if anti- $H$ pylori treatment is irresponsibly widely used, it is best to restrict it to those patients with peptic ulcer disease who can be shown to improve.

The side-effects of vigorous antibiotic treatment can be severe for occasional patients and include pseudomembranous colitis. This risk is only acceptable where proven benefit can be expected.

MC BATESON

General Hospital, Bishop Aukland, County Durham DL14 6AD, UK

11 Xia H, Keane CT, Beattie S, O'Morain CA. Standardisation of disk diffusion test and its clinical significance for susceptibility testing of metronidazole against Helicobacter pylori. Antimicrob Agents Chemother 1994; 38: 2357-61.

12 Van Zwet AA, Thijs JC, De Graaf B. Explanations for high rates of eradication with triple therapy using metronidazole in patients harbouring metronidazole-resistance Helicobacter pylori strains. Antimicrob Agents Chemother 1995; 39: 250-2.

13 European Helicobacter Pylori Study Group. VIIIth International Workshop on gastro-duodenal pathology and Helicobacter pylori. Gut 1995; 37: Al-103.

14 Bayerdörffer E, Neubauer A, Rudolph B, et al. Regression of primary gastric lymphoma of mucosa-associated lymphoid tissue type after cure of lymphoma of mucosa-associated lymphoid tissue type after cure of

Helicobacter pylori infection. Lancet 1995; 345: 1591-4.

Berner A-I, Burhol PG. Is Helicobacter pylori the cause of dyspepsia? BMF 1992; 304: 1276-8.

16 Patchett S, Beattie, Leen E, Keane C, O'Moran C. Eradicating Helicobacter pylori and symptoms of non-ulcer dyspepsia. BMF 1991; 303: 1238-40.

17 Gad A, Hradsky M, Furugard K, Malmodin B, Nyberg O. Campylobacter pylori and non-ulcer dyspepsia. Scand $\mathcal{F}$ Gastroenterol 1989; 24 (suppl 167): 44-8.

18 Rokkas T, Karameris A, Mavrogeorgis A, Rallis E, Giannikos N. Eradiation of Helicobacter pylori reduces the possibility of rebleeding in peptic ulcer disease. Gastrointest Endosc 1995; 41: 1-4.

19 Jaspersen D, Koerner T, Schorr W, Brennenstuhl M, Raschka C, Hamma $\mathrm{CH}$. Helicobacter pylori eradication reduces the rate of rebleeding in ulcer haemorrhage. Gastrointest Endosc 1995; 41: 5-7. 